\title{
Eosinophilic airway inflammation induced by repeated exposure to cigarette smoke
}

\author{
K. Matsumoto, H. Aizawa, H. Inoue, H. Koto, S. Takata, M. Shigyo, H. Nakano, N. Hara
}

Eosinophilic airway inflammation induced by repeated exposure to cigarette smoke. K. Matsumoto, H. Aizawa, H. Inoue, H. Koto, S. Takata, M. Shigyo, H. Nakano, N. Hara. (C)RS Journals Ltd 1998.

ABSTRACT: Acute exposure to cigarette smoke causes airway hyperresponsiveness (AHR) in guinea-pigs, which resolves within a few hours. Repeated exposure may have a different effect on the airways.

To address this question, guinea-pigs were repeatedly exposed to cigarette smoke

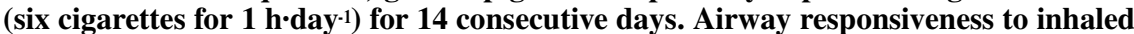
histamine and differential cell counts in bronchoalveolar lavage fluid (BALF) were evaluated 1 day after the last exposure.

Significant neutrophilia in BALF was observed after 3 days of smoke exposure. Significant eosinophilia in BALF and AHR were observed after 14 days of smoke exposure, but not after 3 or 7 days of smoke exposure. These changes persisted until 3 days after the last exposure and resolved 7 days afterwards. Histologically, the recruited eosinophils were observed predominantly in the airways, but not in the alveoli. Treatment with E-6123, a specific platelet-activating factor receptor antago-

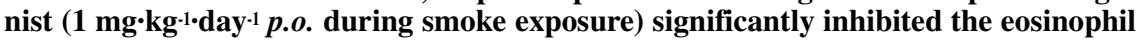
influx and AHR.

Repeated exposure to cigarette smoke may induce prolonged airway inflammation and airway hyperresponsiveness in guinea-pigs. Platelet-activating factor or plateletactivating factor-like lipids may play a key role in airway hyperresponsiveness, presumably by the induction of essinophilic airway inflammation.

Eur Respir J 1998; 12: 387-394.
Research Institute for Diseases of the Chest, Faculty of Medicine, Kyushu University, Fukuoka, Japan.

Correspondence: H. Aizawa

Research Institute for Diseases of the Chest Faculty of Medicine

Kyushu University

3-1-1 Maidashi

Higashiku

Fukuoka 812-8582

Japan

Fax: 81926425389

Keywords: Airway hyperresponsiveness E-6123

platelet-activating factor

receptor antagonist

Received: September 241997

Accepted after revision April 121998
Airway hyperresponsiveness, a characteristic of asthma, is known to be associated with airway inflammation [1]. In order to clarify the underlying mechanisms of airway inflammation and hyperresponsiveness, several experimental models have been employed, including allergen-challenged, ozone-exposed and cigarette smoke-exposed models [2-7].

Acute exposure to cigarette smoke causes airway hyperresponsiveness in guinea-pigs [4-7]. However, this airway hyperresponsiveness resolves within a few hours [4, 6]. Results obtained from the acute experimental models might not be fully extrapolated to the persistent airway hyperresponsiveness observed in asthmatic subjects.

To establish a prolonged airway hyperresponsiveness model, guinea-pigs were exposed repeatedly to cigarette smoke for 14 consecutive days. This protocol induced airway hyperresponsiveness, lasting at least 3 days; which was concurrent with eosinophilic airway inflammation. These findings raised the possibility that airway hyperresponsiveness induced by repeated exposure may be linked to the eosinophilic airway inflammation. A previous study reported that cigarette smoke increases the levels of plateletactivating factor (PAF)-like lipid(s) in plasma in humans [8]. It is conceivable that PAF or PAF-like lipids may be possible mediators responsible for the eosinophilic airway inflammation and hyperresponsiveness, since PAF has eosinophilic chemotactic activity in vitro $[9,10]$, and could induce airway hyperresponsiveness in vivo [11-13]. To test the above hypothesis, the effect of a specific PAF receptor antagonist, E-6123 [14, 15], was evaluated in this experimental model.

\section{Materials and methods}

Animals

Male Hartley-strain guinea-pigs weighing 500-600 g (Kyudo, Kumamoto, Japan) were randomly divided into several groups ( $\mathrm{n}=5$ per group) as follows.

\section{Study protocols}

Study 1. Animals were divided into three groups and experiments were performed after a single cigarette smoke exposure (six cigarettes for $1 \mathrm{~h}$ ), according to the method described below. Measurements of airway responsiveness and bronchoalveolar lavage (BAL) were performed at 1, 6 or $24 \mathrm{~h}$ after the exposure. Other animals served as shamexposed controls.

Study 2. Animals were divided into three groups and exposed repeatedly to cigarette smoke (six cigarettes for 1 
h, once daily) for 3, 7 or 14 days. Measurements of airway responsiveness and BAL were performed 1 day after the last exposure. Other animals served as sham-exposed controls.

Study 3. Animals were divided into three groups and exposed repeatedly to cigarette smoke for 14 days. Measurements of airway responsiveness and BAL were performed 1,3 or 7 days after the last exposure. Other animals served as sham-exposed controls.

Study 4. Animals were divided into four groups as follows: 1) sham exposure with vehicle treatment, 2) sham exposure with E-6123 treatment, 3) repeated exposure with vehicle treatment, and 4) repeated exposure with E-6123 treatment. Animals were exposed repeatedly to cigarette smoke for 14 days. Other animals served as sham-exposed controls. Measurements of airway responsiveness and BAL were performed 1 day after the last exposure. E-6123 (1 $\left.\mathrm{mg} \cdot \mathrm{kg}^{-1} \cdot \mathrm{day}^{-1}\right)$ or vehicle was orally administered $3 \mathrm{~h}$ before the exposure to cigarette smoke or sham each day. The dose of E-6123 was based on previous reports [14, $15]$.

Study 5. Three animals were exposed repeatedly to cigarette smoke for 14 days and were used for histopathological examination 1 day after the last exposure. Three animals served as sham-exposed controls.

\section{Exposure to cigarette smoke}

Animals were placed in a $125 \mathrm{~L}$ chamber made of plexiglas and exposed to diluted cigarette smoke in an awake and unrestrained state. The chamber had three holes of 3$5 \mathrm{~mm}$ in diameter. An exhaust hole on the top of the panel was connected to a vacuum system which could generate constant vacuum flow $\left(20 \mathrm{~L} \cdot \mathrm{min}^{-1}\right)$. A cigarette was attached to an inlet hole on the front panel. The remaining hole on the front panel was used as a fresh air inlet. With constant vacuum flow, the smoke stream was drawn into the chamber and mixed with fresh air. One cigarette took 5 min to burn and was then immediately detached from the chamber. The visible smoke disappeared over the next 5 min. Animals were exposed to six cigarettes for $1 \mathrm{~h} \cdot \mathrm{day}^{-1}$. The cigarettes were purchased from Japan Tobacco Co. (Tokyo, Japan). According to the manufacturer's specifications, each cigarette contained $2.7 \mathrm{mg}$ of nicotine and $26 \mathrm{mg}$ of tar.

\section{Measurement of total pulmonary resistance}

Guinea-pigs were anaesthetized i.p. with $50 \mathrm{mg} \cdot \mathrm{kg}^{-1}$ pentobarbital sodium. Animals were intubated via tracheostomy and mechanically ventilated with a respirator (Model No. 680, Harvard Apparatus, South Natick, MA, USA) at a constant tidal volume of $7 \mathrm{~mL} \cdot \mathrm{kg}^{-1}$ and a rate of 60 breaths $\cdot \mathrm{min}^{-1}$. To evaluate pleural pressure, a fluid-filled catheter was introduced into the oesophagus at a point such that the maximal amplitude of pressure was obtained. The animals were placed supine in a body plethysmograph and the plethysmograph airflow was measured with a Fleisch pneumotachograph (TV-132T; Nihon Koh- den, Tokyo, Japan) and a differential pressure transducer (TP-602T, Nihon Kohden). The plethysmograph was made of plexiglas and had $2.80 \mathrm{~L}$ of dead space (customized; Chest Medical, Tokyo, Japan). Transpulmonary pressure $(P$ tp) was estimated as the difference between the oesophageal and airway opening pressure, measured by a differential pressure transducer (TP-603T; Nihon Kohden). Total pulmonary resistance $(R \mathrm{~L})$ was calculated from $P$ tp and airflow.

\section{Measurement of airway responsiveness}

Airway responsiveness to histamine was determined by inhalation of an increasing concentration of histamine administered via the endotracheal tube. Histamine aerosols (output, $1.5 \mathrm{~mL} \cdot \mathrm{min}^{-1}$ ) were generated by an ultrasonic nebulizer (TUR-3200; Nihon Kohden) placed in-line with the ventilator. Dose-response curves were constructed as follows: saline aerosol was given for 15 breaths and the subsequent $R \mathrm{~L}$ value was used as a baseline. The histamine aerosol was administered for 15 breaths, separated by $5 \mathrm{~min}$ intervals. The concentration of histamine was increased for each series of 15 breaths. $R \mathrm{~L}$ was monitored for $5 \mathrm{~min}$ after each nebulization and the maximum value was plotted against histamine concentration. To achieve a constant-volume history, hyperinflations (triplicate of tidal volumes) were obtained between each histamine challenge. The challenge was halted when $R \mathrm{~L}$ exceeded $200 \%$ of baseline. The provocative concentration of histamine required to produce a $200 \%$ increase in $R \mathrm{~L}$ (PC200) was calculated by log-linear interpolation from individual animals.

\section{Bronchoalveolar lavage}

Animals were killed by exsanguination. The lung was gently lavaged three times with normal saline via the tracheal cannula at a pressure of $2.45 \mathrm{kPa}$. Total cell counts were determined under light microscopy with a standard haemocytometer. The lavage fluid was centrifuged at 200 $\times \mathrm{g}$ for $10 \mathrm{~min}$ at $4^{\circ} \mathrm{C}$. The cell pellet was resuspended in normal saline to obtain a suspension of $10^{5}$ cells $\cdot \mathrm{mL}^{-1}$. Cytospin preparations (Cytospin 3, Shandon, Pittsburgh, PA, USA) were made and the cells were visualized with a modified Wright-Giemsa stain (Diff-Quick, Baxter, McGaw Park, IL, USA). Differential counts on 500 cells were performed in a blind fashion under light microscopy.

\section{Histopathological assessment}

To avoid possible traumatic damage due to histamine-induced bronchoconstriction or BAL, histopathological assessment in airway and lung tissue was made in separate animals. Animals were anaesthetized i.p. with 50 $\mathrm{mg}^{-1} \cdot \mathrm{kg}$ pentobarbital sodium and exsanguinated. The cervical trachea and the lungs were removed en bloc. A cannula was introduced into the proximal portion of the trachea and the lungs were distended with buffered formalin applied at a constant pressure of $2.45 \mathrm{kPa}$. Both main bronchi and the parenchyma of the right caudal lobe were dissected out and embedded in paraffin. Sections $(5 \mathrm{~mm}$ 
thick) were cut from each sample and stained with haematoxylin and eosin. Histopathological assessment (light microscopy) was performed in a blind fashion on randomized sections.

\section{Drugs}

Pentobarbital sodium was obtained from Abbott (North Chicago, IL, USA). Histamine diphosphate was obtained from Sigma Chemical Co. (St Louis, MO, USA). (S)-(+)-6(2-chlorophenyl)-3-cyclopropanecarbonyl-8,11-dimethyl2,3,4,5-tetrahydro-8H-pyrido[4',3':4,5]thieno[3,2-f][1,2,4] triazolo[4,3-a][1,4]diazepine (E-6123) was provided by Eisai Pharmaceutical (Tokyo, Japan) and was dissolved in 100\% ethanol at a concentration of $10 \mathrm{mg} \cdot \mathrm{mL}^{-1}$, then diluted in $0.9 \%$ saline to a final concentration of $1 \mathrm{mg} \cdot \mathrm{mL}^{-1}$.

\section{Data analysis}

PC200 values are expressed as $\log \left(\mathrm{PC}_{200} \times 100\right)$. Other values are expressed as the arithmetic mean and standard error (SEM). PC200 values were compared by one-way analysis of variance (ANOVA) with the Bonferoni correction. Changes in the BAL cell counts were compared by the Kruskall-Wallis H-test followed by the Mann-Whitney U-test. A level of $\mathrm{p}<0.05$ was accepted as statistically significant.

\section{Results}

Time course of airway responsiveness and pro-inflammatory cell counts in BAL fluid after a single exposure to cigarette smoke

Figure 1 illustrates the effects of a single exposure to cigarette smoke on airway responsiveness and pro-inflammatory cell profiles in BAL fluid (BALF). Compared with sham-exposed controls, there was no significant changes in airway responsiveness at 1,6 or $24 \mathrm{~h}$ after smoke exposure (fig. 1a). The number of eosinophils in BALF also showed no significant change after exposure (fig. 1b). Significant neutrophilia was observed $1 \mathrm{~h}$ after exposure (fig. 1c). There was no significant change in the number of macrophages and lymphocytes in the BALF (data not shown).

Effect of repeated exposure to cigarette smoke on airway responsiveness and pro-inflammatory cell counts in $B A L F$

Figure 2 illustrates the effects of repeated exposure to cigarette smoke on airway responsiveness and cell profiles in BALF. Compared with sham-exposed controls, there was no significant change in airway responsiveness after 3 or 7 days of repeated smoke exposure. However, after 14 days of repeated exposure, airway responsiveness increased significantly (fig. 2a). Significant eosinophilia in BALF was also noted after 14 days, but not after 3 or 7 days (fig. 2b). Significant neutrophilia had already been observed after 3 days of exposure, with no further increase after this (fig. 2c). There was no significant change in the number of macrophages and lymphocytes in the BALF (table 1).

Time course of airway responsiveness and pro-inflammatory cell counts in BALF after repeated exposure to cigarette smoke

Figure 3 illustrates the time course of airway responsiveness and cell profiles in BALF after the last exposure in animals exposed for 14 days. The cigarette smoke-induced airway hyperresponsiveness persisted until 3 days after the last exposure and resolved 7 days later (fig. 3a). Similarly, the eosinophila and neutrophilia persisted until 3 days after the last exposure and returned to baseline values 7 days later (fig. $3 \mathrm{~b}$ and $3 \mathrm{c}$ ). There was no significant change in the number of macrophages and lymphocytes in the BALF (data not shown).
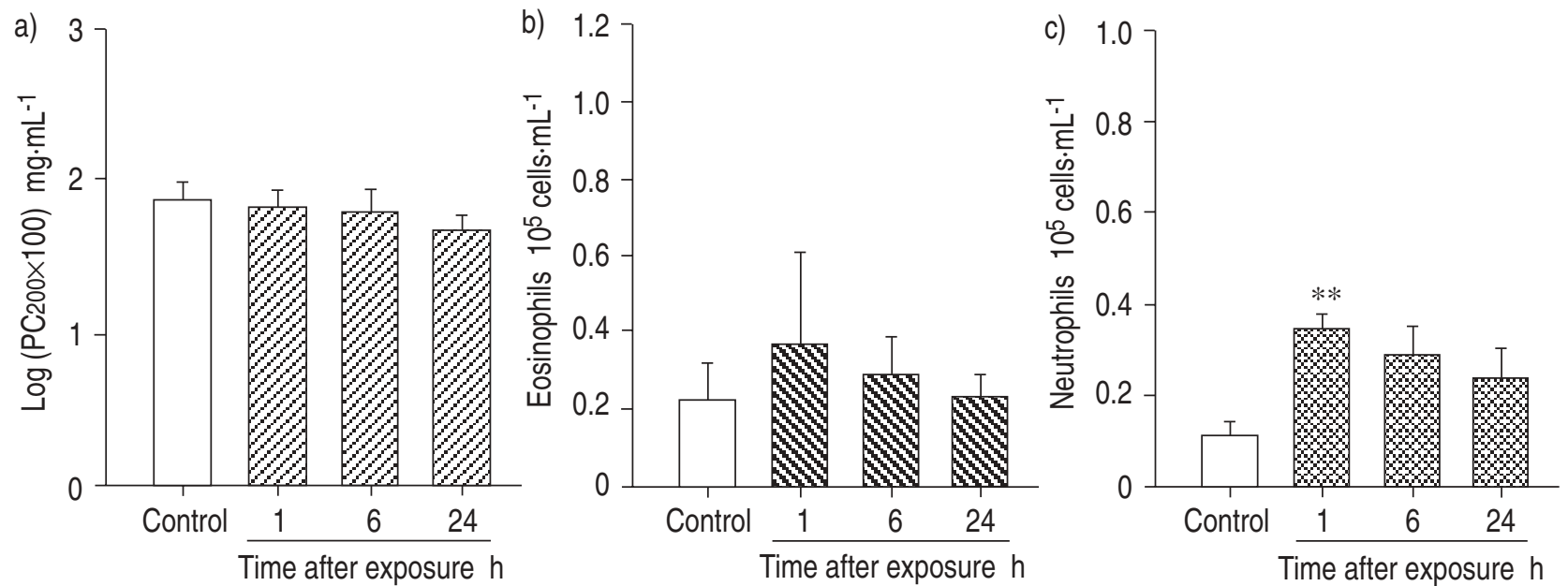

Fig. 1. - Time course of airway responsiveness and pro-inflammatory cell counts in bronchoalveolar lavage fluid (BALF) after a single exposure to cigarette smoke. a) There was no significant change in airway responsiveness 1,6 and $24 \mathrm{~h}$ after smoke exposure, compared with the sham-exposed controls. b) The number of eosinophils in BALF showed no significant change 1, 6 and $24 \mathrm{~h}$ after exposure. c) Significant neutrophilia was observed at $1 \mathrm{~h}$, but not at 6 or $24 \mathrm{~h}$ after exposure. PC200: provocative concentration of histamine required to produce a $200 \%$ increase in pulmonary resistance. $* *$ : $\mathrm{p}<0.01$. 


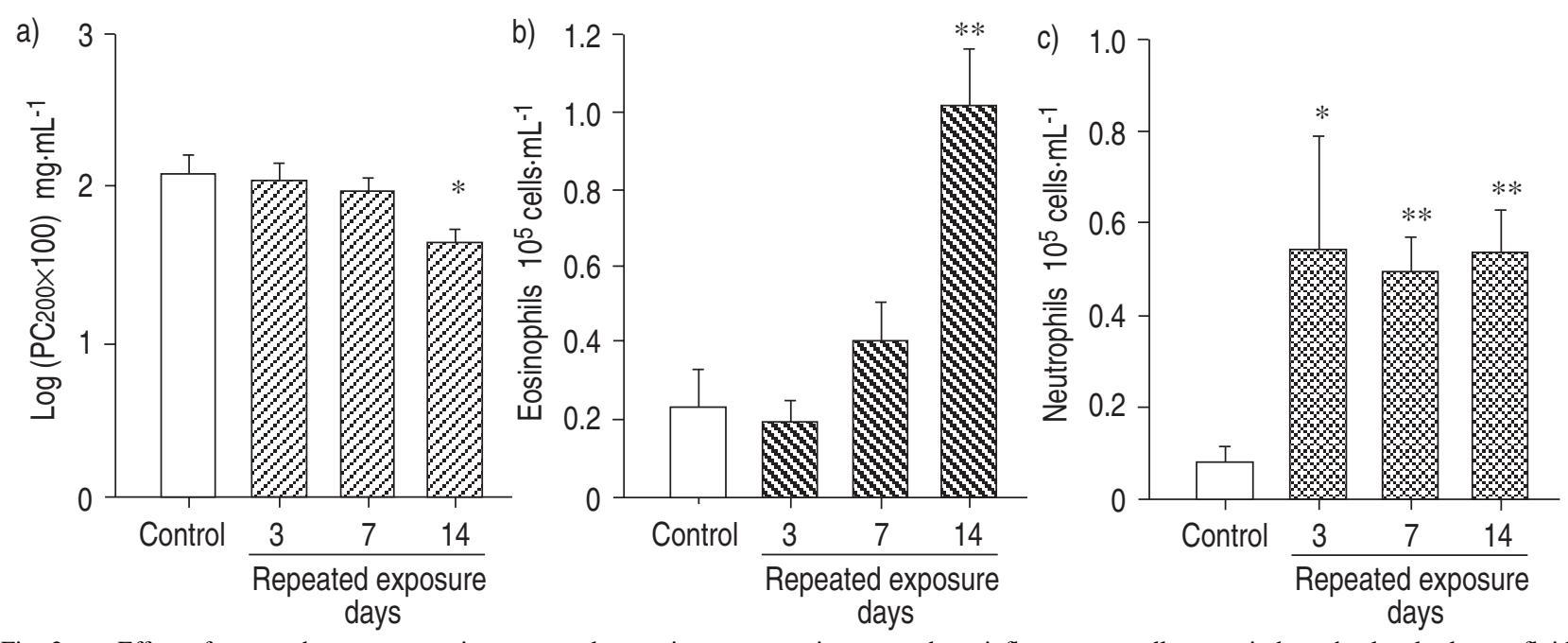

Fig. 2. - Effect of repeated exposure to cigarette smoke on airway responsiveness and pro-inflammatory cell counts in bronchoalveolar lavage fluid (BALF). a) There was no significant change in airway responsiveness after 3 or 7 days of smoke exposure, compared with the sham-exposed controls. After 14 days of exposure, the airway responsiveness increased significantly. b) Significant eosinophilia in BALF was noted after 14 days of smoke exposure, but not after 3 or 7 days of smoke exposure. c) Significant neutrophilia was observed 3 days of exposure, but the cell numbers remained unchanged on the following days of exposure. PC200: provocative concentration of histamine required to produce a $200 \%$ increase in pulmonary resistance. $*: \mathrm{p}<0.05 ; * *: \mathrm{p}<0.01$

Table 1. - Effects of repeated exposure to cigarette on the number of macrophages and lymphocytes

\begin{tabular}{ccccc}
\hline Treatment & Sham & 1 day & 3 days & 7 days \\
\hline $\begin{array}{c}\text { Macrophages } \\
10^{5} \text { cells } \cdot \mathrm{mL}^{-1}\end{array}$ & $2.28 \pm 0.34$ & $2.64 \pm 0.13$ & $2.56 \pm 0.29$ & $2.58 \pm 0.35$ \\
$\begin{array}{c}\text { Lymphocytes } \\
10^{5} \text { cells } \cdot \mathrm{mL}^{-1}\end{array}$ & $0.17 \pm 0.04$ & $0.15 \pm 0.04$ & $0.16 \pm 0.09$ & $0.25 \pm 0.07$ \\
\hline
\end{tabular}

Effect of E-6123 on airway hyperresponsiveness and increases in pro-inflammatory cell numbers in BALF induced by repeated exposure to cigarette smoke

Figure 4 illustrates the effects of E-6123 treatment on airway hyperresponsiveness, eosinophilia and neutrophilia induced by 14 days of repeated exposure to cigarette smoke. E-6123 treatment itself had no effect on airway responsiveness in sham-exposed animals. E-6123 treatment, however, significantly inhibited cigarette smoke-induced airway hyperresponsiveness (fig. 4a). E-6123 treatment had no effect on the number of eosinophils and neutrophils in sham-exposed animals. The cigarette smoke-induced eosinophilia and neutrophilia were significantly suppressed by treatment with E-6123 (fig. 4b and c).

Histopathological findings of eosinophil infiltration in tissues of airways and alveoli

Compared with sham-exposed controls, eosinophils were observed frequently in the mucosa of the main bronchi of cigarette smoke-exposed animals (fig. 5a and b). In contrast, eosinophils were scarce in the alveoli of sham- and smoke-exposed animals (fig. 5c and d). Neutrophils could not be evaluated because of difficulties in the identification of their cell bodies in the tissue stained with haematoxylin and eosin.
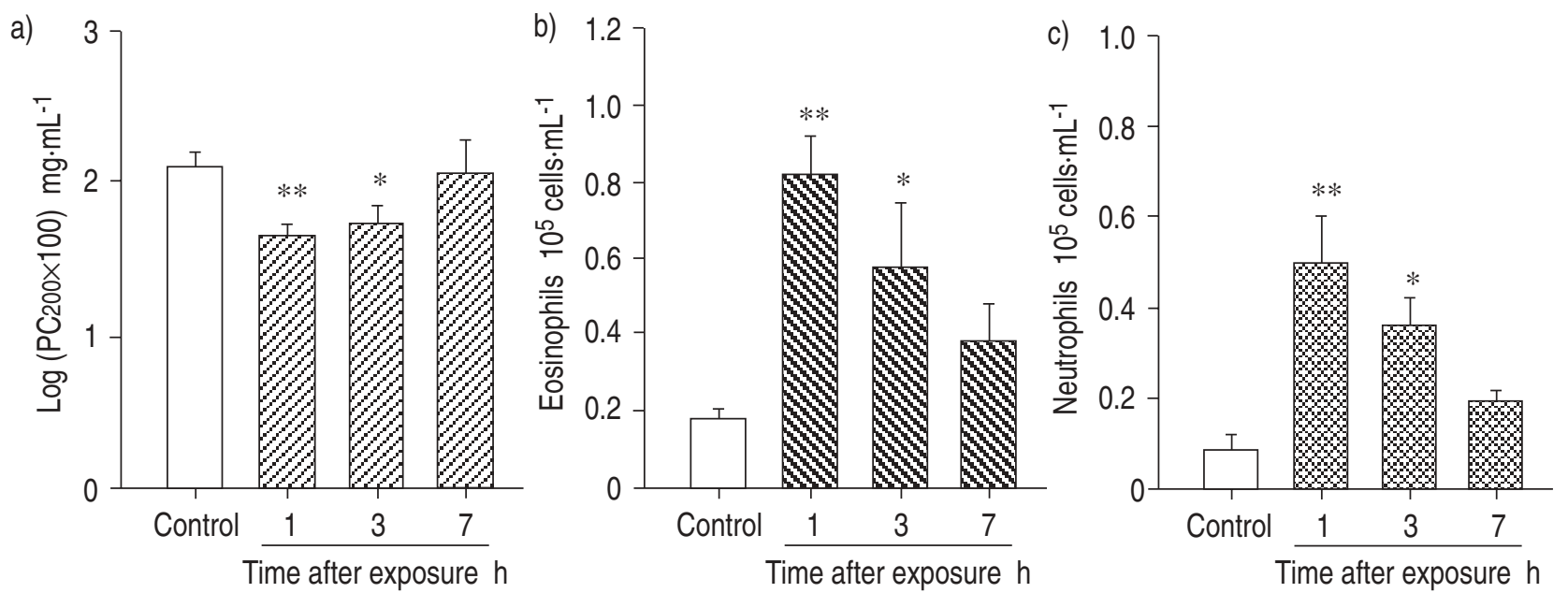

Fig. 3. - Time-course of airway responsiveness and pro-inflammatory cell counts in bronchoalveolar lavage fluid (BALF) after cessation of repeated exposure to cigarette smoke. a) Cigarette smoke-induced airway hyperresponsiveness persisted 3 days after the last exposure but was diminished by 7 days. b) Eosinophilia and c) neutrophilia persisted 3 days after the last exposure but had returned to the baseline value by 7 days. PC200: provocative concentration of histamine required to produce a $200 \%$ increase in pulmonary resistance. $*: \mathrm{p}<0.05 ; * *: \mathrm{p}<0.01$. 

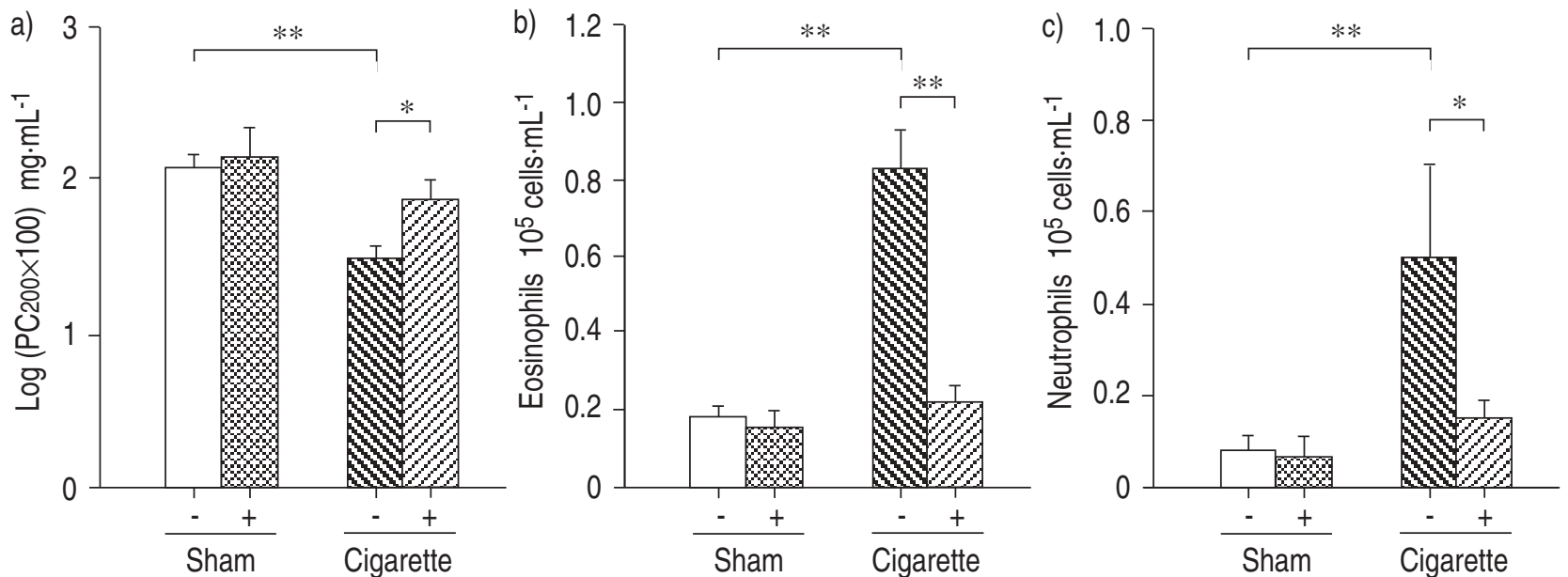

Fig. 4. - Effect of E-6123 on airway hyperresponsiveness and pro-inflammatory cell counts in bronchoalveolar lavage fluid (BALF) induced by repeated exposure to cigarette smoke. a) E-6123 treatment alone had no effect on airway responsiveness in sham-exposed animals. E-6123 treatment, however, significantly inhibited the cigarette smoke-induced airway hyperresponsiveness. E-6123 treatment had no effect on eosinophil (b) and neutrophil (c) cell number in sham-exposed animals. -: without E-6123; +: with E-6123. The cigarette smoke-induced eosinophilia and neutrophilia were significantly suppressed by treatment with E-6123. PC200: provocative concentration of histamine required to produce a $200 \%$ increase in pulmonary resistance. *: $\mathrm{p}<0.05 ; * *: \mathrm{p}<0.01$.
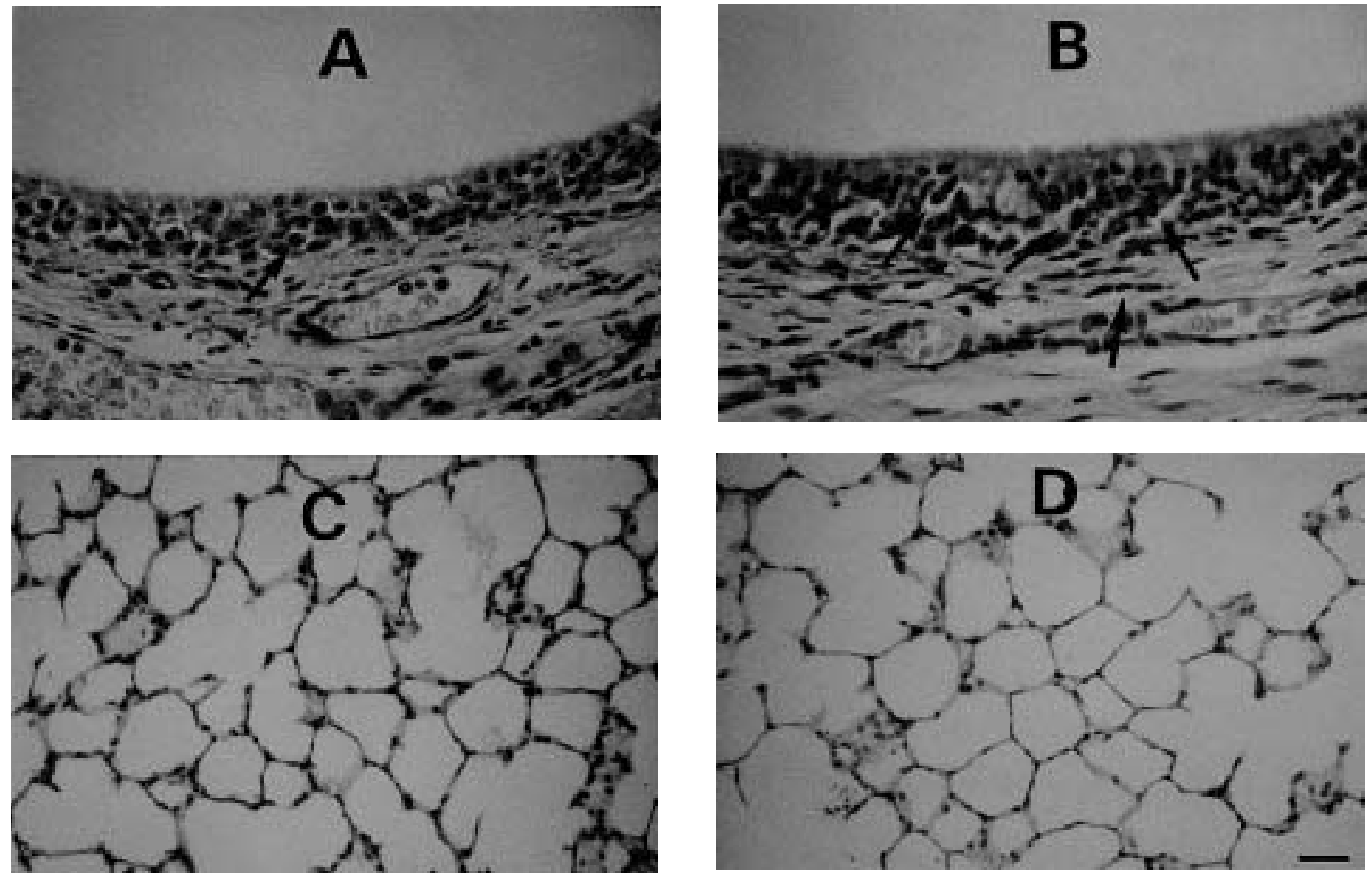

Fig. 5. - Eosinophil infiltration in airway tissue and alveoli. Compared with sham-exposed controls (A), eosinophils (arrows) were observed frequently in the mucosa of the main bronchi of cigarette smoke-exposed guinea-pigs (B). In contrast, eosinophils were scarce in both the alveoli of sham-exposed (C) and smoke-exposed (D). (Internal scale bar: $\mathrm{A}$ and $\mathrm{B}=60 \mu \mathrm{m}, \mathrm{C}$ and $\mathrm{D}=80 \mu \mathrm{m}$, haematoxylin and eosin staining.)

\section{Discussion}

The present study demonstrated that 14 days of repeated exposure to cigarette smoke induced airway hyperresponsiveness which persisted for at least 3 days after the last exposure in guinea-pigs.
In this model, significant eosinophilia in BALF was observed, paralleled by on increase in airway hyperresponsiveness. The histopathological study revealed that recruited eosinophils were observed predominantly in mucosal tissue in the airways, but not in the alveoli, indicating the development of eosinophilic airway inflammation. Previous 
studies have suggested that neutrophilic airway inflammation may be responsible for airway hyperresponsiveness induced by acute exposure to cigarette smoke or ozone $[7,16,17]$. In the present study, neutrophils had already increased $1 \mathrm{~h}$ after a single exposure and after 3 days of repeated exposure, although airway responsiveness did not change. The increased number of neutrophils persisted without any change on the following days of exposure, while airway hyperresponsiveness increased. It seems likely that recruited eosinophils, rather than neutrophils, were predominantly involved in prolonged airway hyperresponsiveness induced by repeated exposure.

A considerable number of studies have suggested the importance of eosinophils in the development of airway hyperresponsiveness [18-21]. It was hypothesized that PAF or PAF-like lipids may play a role in producing eosinophilic airway inflammation and hyperresponsiveness for the following reasons. Firstly, it has been reported that cigarette smoke increases the levels of PAF-like lipids in plasma [8]. Secondly, PAF has strong eosinophil chemotactic activity in vitro $[9,10]$. Thirdly, activated eosinophils per se release PAF in response to various stimuli [22]. Finally, inhaled PAF can induce prolonged airway hyperresponsiveness and inflammation in vivo [11-13]. To test the above hypothesis, the effects of a specific PAF receptor antagonist, E-6123, were explored. The inhibitory effect of E-6123 observed in the present study strongly suggests that intrinsic PAF or PAF-like lipids are important mediators in the induction of eosinophilic airway inflammation and hyperresponsiveness induced by repeated exposure to cigarette smoke.

The precise mechanism by which PAF causes airway inflammation and hyperresponsiveness in this model remains uncertain. PAF may induce airway hyperresponsiveness through the recruitment and activation of eosinophils. It is well documented that PAF is both a chemoattractant and a potent activator of eosinophils [23]. Activated eosinophils release stored granules, such as major basic protein (MBP), eosinophil cationic protein (ECP) and eosinophil peroxidase (EPO) [24]. These granules reportedly cause impairment of airway epithelium $[18,25]$ and cause airway inflammation [26], which may result in airway hyperresponsiveness. Furthermore, recent investigations have shown that PAF, which may be rapidly synthesized by the stimulated endothelial cells, plays a crucial role in adhesion and signalling of vascular cell-to-cell interactions, as the first step of granulocyte transmigration into the extravascular tissues [27-29]. Alternatively, PAF reported-ly induces the production of thromboxane and peptide leukotrienes from airway tissues and pro-inflammatory cells $[12,30]$. These compounds may be responsible for the induction of airway hyperresponsiveness [16, 31, 32]. Thus, multiple mechanisms may be involved in the PAF-mediated development of airway hyperresponsiveness in-duced by repeated exposure.

It is important to explain why the development of eosinophilic airway inflammation and airway hyperresponsiveness required 14 days of repeated exposure. One possible explanation is a positive feedback system that amplifies the production of PAF, resulting in the release of sufficient amounts of PAF to induce airway hyperresponsiveness [22]. Thus, in the early phase, cigarette smoke may cause a release of a small amount of PAF from the airway tissue, which elicits eosinophil chemotaxis. The recruited eosinophils may release more PAF in response to the stimulation by subsequent exposure to smoke. Extended investigation is necessary to confirm this hypothesis.

The clinical importance of the present findings is uncertain. Airway hyperresponsiveness, which is observed persistently in asthmatic subjects, is closely correlated with eosinophilic airway inflammation [1]. In the present study, we have established the prolonged model of eosinophilic airway inflammation and hyperresponsiveness, which is different from the acute exposure models. Acute exposure to cigarette smoke is known to cause airway hyperresponsiveness in guinea-pigs [4-7]. However, this airway hyp-erresponsiveness resolves within a few hours and does not accompany eosinophilic airway inflammation. Acute ex-posure models might not fully address the relationship between eosinophilic airway inflammation and hyperresponsiveness in humans. The present protocol may provide one of the experimental models to investigate how the eosinophilic airway inflammation could contribute to prolonged airway hyperresponsiveness.

In asthmatics, a recent report has revealed that cigarette smoking enhances airway responsiveness to histamine as well as eosinophil and neutrophil activities, thus causing resistance to inhaled steroid therapy [33]. In this regard, the present experimental model may be adequate to investigate the effect of cigarette smoking on airway inflammation and airway hyperresponsiveness in asthmatics.

In another point of view, the presented model would be more accurately a model for airway hyperresponsiveness associated with chronic obstructive pulmonary disease (COPD). It is well known that COPD is associated with cigarette smoking. Mild-to-moderate airway hyperresponsiveness is frequently observed in patients with COPD [34]. Recently, it has been revealed that eosinophilic airway inflammation is a significant finding in patients with chronic bronchitis [35-37]. Although the exact mechanisms for the development of eosinophilic airway inflammation and hyperresponsiveness in COPD is known, the results of this investigation might suggest one of the possible mechanisms.

Several investigators have reported that chronic passive smoking induced airway hyperresponsiveness in guineapigs [38, 39]. In contrast, KARLSSON et al. [40] reported that chronic active exposure to cigarette smoke induced hyperresponsiveness to tussive stimuli, but not to a bronchoconstrictor, histamine. In this study, the animals were exposed to cigarette smoke in a chamber where the total body is exposed. This model might be concerned with the one of passive smoking rather than active smoking. In this regard, another point needs to be considered. While the previous studies of passive smoking used the sidestream of cigarette smoke, the present model used the mainstream, which may rather resemble active smoking models. It is possible that both exposure pattern and source of smoke have considerable effects on the results of these investigations. To elucidate this issue, further studies are needed.

This study was started based on previous experience about acute exposure models [7, 41, 42]. When anaesthetized guinea-pigs were acutely exposed to less diluted smoke through the tracheostomy tube for $10 \mathrm{~min}$, marked bronchoconstriction occurred within a few minutes [41, 42]. When exposing animals to more diluted smoke for only $3 \mathrm{~min}$, it did not cause direct bronchoconstriction, but induced significant airway hyperresponsiveness to inhaled 
histamine [7]. It has been established that the effect of cigarette smoke on airway responsiveness is dose-dependent [4-6]. In this study, the smoke was extremely diluted in a large chamber, and acute exposure did not induce airway hyperresponsiveness in spite of a $1 \mathrm{~h}$ of exposure duration. Therefore, it was assumed that the condition of exposure may be milder than that elicited in previous studies. Although the best method to estimate the burden of smoke exposure may be to measure the amount of carboxyhaemoglobin (HB-CO) in blood immediately after exposure, no data on HB-CO were available in this study.

In summary, repeated exposure to cigarette smoke induced prolonged airway hyperresponsiveness with eosinophilic airway inflammation in guinea-pigs. These changes were significantly inhibited by pretreatment with E-6123, a specific platelet-activating factor receptor antagonist. Intrinsic platelet-activating factor may play an important role in airway hyperresponsiveness induced by repeated exposure to cigarette smoke, possibly by the induction of eosinophilic airway inflammation in guinea-pigs.

Acknowledgements: The authors are grateful to Eisai Pharmaceutical for the donation of E-6123.

\section{References}

1. National Heart, Lung, and Blood Institute. Global strategy for asthma management and prevention, NHLBI/WHO workshop report. Publication No. 95-3659. Bethesda, MD, National Institute of Health, January 1995.

2. Elwood W, Lötvall JA, Barnes PJ, Chung KF. Characterization of allergen-induced bronchial hyperresponsiveness and airway inflammation in actively sensitized BrownNorway rats. J Allergy Clin Immunol 1991; 88: 951-960.

3. Fabbri LM, Aizawa H, Alpert SE, et al. Airway hyperresponsiveness and changes in cell counts in bronchoalveolar lavage after ozone exposure in dogs. Am Rev Respir Dis 1984; 129: 288-291.

4. Hulbert WM, Mclean T, Hogg JC. The effect of acute airway inflammation on bronchial reactivity in guinea pigs. Am Rev Respir Dis 1985; 132: 7-11.

5. Dusser DJ, Djokic TD, Borson DB, Nadel JA. Cigarette smoke induces bronchoconstrictor hyperresponsiveness to substance $\mathrm{P}$ and inactivates airway neutral endopeptidase in the guinea pig: possible role of free radicals. $J$ Clin Invest 1989; 84: 900-906.

6. Nishikawa M, Ikeda H, Fukuda T, Suzuki S, Okubo T. Acute exposure to cigarette smoke induces airway hyperresponsiveness without airway inflammation in guinea pigs: dose-response characteristics. Am Rev Respir Dis 1990; 142: 177-183.

7. Matsumoto K, Aizawa H, Inoue H, Shigyo M, Takata S, Hara N. Thromboxane causes airway hyperresponsiveness after cigarette smoke-induced neurogenic inflammation. J Appl Physiol 1996; 81: 2358-2364.

8. Imaizumi T, Satoh K, Yoshida H, Kawamura H, Hiramoto M, Takamatsu S. Effect of cigarette smoking on the levels of platelet-activating factor-like lipid(s) in plasma lipoproteins. Atherosclerosis 1991; 87: 47-55.

9. Wardlaw AJ, Moqbel R, Cromwell O, Kay AB. Platelet-activating factor: a potent chemotactic and chemokinetic factor for human eosinophils. J Clin Invest 1986; 78: 1701-1706.

10. Little MM, Casale TB. Comparison of platelet-activating factor-induced chemotaxis of normodense and hypodense eosinophils. J Allergy Clin Immunol 1991; 88: 187-192.
11. Mazzoni L, Morley J, Page CP, Sanjar S. Introduction of airway hyperreactivity by platelet-activating factor in the guinea-pig. J Physiol 1985; 365: 107.

12. Chung KF, Aizawa H, Leikauf GD, Ueki IF, Evans TW, Nadel JA. Airway hyperresponsiveness induced by platelet-activating factor. Role of thromboxane generation. $J$ Pharmacol Exp Ther 1986; 236: 580-584.

13. Cuss FM, Dixon CMS, Barnes PJ. Effect of inhaled platelet-activating factor on pulmonary function and bronchial hyperresponsiveness in man. Lancet 1986; ii: 189-192.

14. Sakuma Y, Tsunoda H, Shirato M, Katayama S, Yamatsu I, Katayama K. Pharmacological effects of oral E-6123, a novel PAF antagonist, on biological changes induced by PAF inhalation in guinea pigs. Prostaglandins 1991; 42: 463-472.

15. Sakuma Y, Muramoto K, Harada K, Katayama S, Tsunoda $\mathrm{H}$, Katayama $\mathrm{K}$. Inhibitory effects of a novel PAF antagonist E-6123 on anaphylactic responses in passively and actively sensitized guinea pigs and passively sensitized mice. Prostaglandins 1991; 42: 541-555.

16. Aizawa H, Chung KF, Leikauf GD, et al. Significance of thromboxane generation in ozone-induced airway hyperresponsiveness in dogs. J Appl Physiol 1985; 59: 1918 1923.

17. Koto H, Aizawa H, Takata S, Inoue H, Hara N. An important role of tachykinins in ozone-induced airway hyperresponsiveness. Am J Respir Crit Care Med 1995; 151: 1763-1769.

18. Flavahan NA, Slifman NR, Gleich GJ, Vanhoutte PM Human eosinophil major basic protein caused hyperreactivity of respiratory smooth muscle. Am Rev Respir Dis 1984; 138: 685-688.

19. Bradley BL, Azzawi M, Jacobson M, et al. Eosinophils, T-lymphocytes, mast cells, neutrophils, and macrophages in bronchial biopsy specimens from atopic subjects with asthma: comparison with biopsy specimens from atopic subjects without asthma and normal control subjects and relationship to bronchial hyperresponsiveness. J Allergy Clin Immunol 1991; 88: 661-674.

20. Uchida DA, Ackerman SJ, Coyle AJ, et al. The effect of human eosinophil granule major basic protein on airway responsiveness in the rat in vivo. Am Rev Respir Dis 1993 147: 982-988.

21. Hamann KJ, Strek ME, Baranowski SL, et al. Effects of activated eosinophils cord blood on guinea pig trachealis. Am J Physiol 1993; 265: L301- L307.

22. Lee TC, Lenihan DJ, Malone B, Roddy LL, Wasserman SI. Increased biosynthesis of platelet-activating factor in activated human eosinophils. J Biol Chem 1984; 259: 5526-5530.

23. Kroegel C, Yukawa T, Dent G, Venge P, Chung KF, Barnes PJ. Stimulation of degranulation from human eosinophils by platelet-activating factor. J Immunol 1989; 142: 3518-3526.

24. Gleich GJ, Flavahan NA, Fujisawa T, Vanhoutte PM. The eosinophil as a mediator of damage to respiratory epithelium: a model for bronchial hyperreactivity. J Allergy Clin Immunol 1988; 81: 776-781.

25. Motojima S, Frigas E, Loegering DA, Gleich GJ. Toxicity of eosinophil cationic proteins for guinea pig tracheal epithelium in vitro. Am Rev Respir Dis 1989; 139: 801-805.

26. Coyle AJ, Perretti F, Manzini S, Irvin CG. Cationic protein-induced sensory nerve activation: role of substance $P$ in airway hyperresponsiveness and plasma extravasation. J Clin Invest 1994; 94: 2301-2306.

27. Zimmermann GA, McIntyre TM, Mehra M, Prescott SM. Endothelial cell-associated platelet-activating factor: a 
novel mechanism for signaling intercellular adhesion. $J$ Cell Biol 1990; 110: 539-540.

28. Casale TB, Erger RA, Little MM. Platelet-activating factor-induced human eosinophil transendothelial migration: evidence for a dynamic role of the endothelium. Am J Respir Cell Mol Biol 1993; 8: 77-82.

29. Lorant DE, Topham MK, Whatley RE, et al. Inflammatory role of P-selectin. J Clin Invest 1993; 92: 559-570.

30. Bruynzeel PLB, Koenderman L, Kok PTM, Hameling ML, Verhagen J. Platelet-activating factor (PAF-aceter) induced leukotriene $\mathrm{C}_{4}$ formation and luminol dependent chemiluminescence by human eosinophils. Pharmacol Res Commun 1986; 18: 61-69.

31. Jones GL, Saroea HG, Watson RM, O'Byrne PM. Effect of an inhaled thromboxane mimetic (U46619) on airway function in human subjects. Am Rev Respir Dis 1992; 145: $1270-1274$.

32. Kaye MG, Smith LJ. Effects of inhaled leukotriene $\mathrm{D}_{4}$ and platelet-activating factor on airway reactivity in normal subjects. Am Rev Respir Dis 1990; 141: 993-997.

33. Pedersen B, Dahl R, Karlstrom R, Peterson CGB, Venge P. Eosinophil and neutrophil activity in a one-year trial with inhaled budesonide: the impact of smoking. Am J Respir Crit Care Med 1996; 153: 1519-1529.

34. Verma VK, Cockcroft DW, Dosman JA. Airway responsiveness to inhaled histamine in chronic obstructive airways disease (chronic bronchitis vs. emphysema). Chest 1988; 94: 457-461.

35. Linden M, Rasmussen JB, Piitulainen E, et al. Airway inflammation in smokers with nonobstructive and obstruc- tive chronic bronchitis. Am Rev Respir Dis 1993; 148: 1226-1232.

36. Lebowitz MD, Postma DS, Burrows B. Adverse effects of eosinophilia and smoking on the natural history of newly diagnosed chronic bronchitis. Chest 1995; 108: 55-61.

37. Riise GC, Ahlstedt S, Larsson S, et al. Bronchial inflammation in chronic bronchitis assessed by measurement of cell products in bronchial lavage fluid. Thorax 1995; 50: 360-365.

38. Lai Y-L, Thacker A, Gairola CG. Sidestream cigarette smoke exposure and airway reactivity during early life. $J$ Appl Physiol 1994; 77: 1868-1874.

39. Bonham AC, Kott KS, Joad JP. Sidestream smoke exposure enhances rapidly adapting receptor responses to substance P in young guinea pigs. J Appl Physiol 1996; 81: $1715-1722$.

40. Karlsson JA, Zackrisson, Lundberg JM. Hyperresponsiveness to tussive stimuli in cigarette smoke-exposed guineapigs: a role for capsaicin-sensitive, calcitonin gene-related peptide-containing nerves. Acta Physiol Scand 1991; 141: 445-454.

41. Matsumoto K, Aizawa H, Shigyo M, Inoue H, Takata S, Hara N. Role of tachykinins in airway narrowing induced by cigarette smoke in guinea pigs. Environ Toxicol Pharmacol 1996; 1: 227-233.

42. Matsumoto K, Aizawa H, Inoue H, Takata S, Shigyo M, Hara N. Role of thromboxane- $\mathrm{A}_{2}$ and cholinergic mechanisms in bronchoconstriction induced by cigarette smoke in guinea-pigs. Eur Respir J 1996; 9: 2468-2473. 